\title{
Effect of hydration on the mechanical properties and ion conduction in a polyethylene-b- poly(vinylbenzyl trimethylammonium) anion exchange membrane
}

Melissa A. Vandiver ${ }^{1}$, Benjamin R. Caire ${ }^{1}$, Tara P. Pandey ${ }^{1}$, Yifan $\mathrm{Li}^{2}$, Sönke Seifert ${ }^{3}$, Ahmet Kusoglu ${ }^{4}$, Daniel M. Knauss ${ }^{2}$, Andrew M. Herring ${ }^{1}$, Matthew W. Liberatore ${ }^{1 *}$

${ }^{1}$ Department of Chemical and Biological Engineering and ${ }^{2}$ Department of Chemistry and Geochemistry, Colorado School of Mines, Golden, CO 80401

${ }^{3}$ X-Ray Science Division, Argonne National Laboratory, Argonne, Illinois 60439

${ }^{4}$ Electrochemical Technologies Group, Lawrence Berkeley National Laboratory, Berkeley, CA 94720

*Corresponding author: mliberat@mines.edu

\begin{abstract}
Anion exchange membranes (AEM) are promising solid polymer electrolytes utilized in alkali fuel cells and electrochemical energy conversion devices. AEMs must efficiently conduct ions while maintaining chemical and mechanical stability under a range of operating conditions. The ionic nature of AEMs leads to stiff and brittle membranes under dry conditions while at higher hydrations, water sorption causes significant softening and weakening of the membrane. In this work, a new polyethylene-b-poly(vinylbenzyl trimethylammonium) polymer $(70 \mathrm{~kg} / \mathrm{mol})$ was cast into large $\left(300 \mathrm{~cm}^{2}\right)$, thin $(12 \pm 3 \mu \mathrm{m})$ membranes. These membranes exhibited improved elasticity over previously tested AEMs, minimal dimensional swelling, and moderate ionic conductivity $\left(5 \pm 2 \mathrm{mS} / \mathrm{cm}\right.$ at $50^{\circ} \mathrm{C}, 95 \% \mathrm{RH}$ in the bromide form). Extensional testing indicated a 95\% reduction in Young's modulus between dry and hydrated states. Further investigation of the complex modulus as a function of hydration, by dynamic mechanical analysis, revealed a sharp decrease in modulus between dry and hydrated states. Mechanical softening was reversible, but the location of the transition displayed hysteresis between
\end{abstract}


humidification and dehumidification. Conductivity increased after membrane softening; suggesting bulk mechanical properties can identify the hydration level required for improved ion transport. Understanding the relationship between ion conduction and mechanical properties will help guide AEM development and identify operating conditions for sustained performance.

\section{Introduction:}

Anion exchange membranes (AEM) can be utilized as solid polymer electrolytes for alkali fuel cells and other electrochemical energy conversion devices such as elctrolyzers and redox flow batteries.[1-3] Compared to proton exchange membrane (PEM) fuel cells alkali AEM energy conversion devices benefit from facile kinetics and opportunities for non-precious metal catalysts.[4-6] As a relatively recent field of study, AEMs for energy conversion face a number of developmental challenges before commercial application can be realized. These challenges include chemical stability of the cationic group and polymer backbone, the possibility of lower ion transport compared to PEMs, and mechanical strength and durability of the membrane. The alkali environment of an AEM exposes the membrane to hydroxide ions that can attack the ionic

group tethered to the polymer or the polymer backbone itself.[3] A significant amount of ongoing research is directed towards identifying alkali stable polymer chemistries and novel cation functionalities for chemically robust AEMs.[7-10] Transport of hydroxide, or other anions, in an AEM is inherently slower than protons in PEMs, and to compensate for this factor, ionic concentration is often increased in AEMs.[1] While increasing ion concentration in AEMs can improve ion conduction, a high ion concentration also increases water sorption in the membrane that can negatively impact mechanical integrity and durability.[2] Additionally, dimensional swelling resulting from water uptake can deform the membrane or cause delamination from catalyst layers. Repeated swelling cycles generate stresses inside the membrane that can create 
pinholes and cracks in the membrane.[11] A successful AEM must efficiently conduct anions and be chemically and mechanically stable over the lifetime of the device, however the complex interplay between these properties requires new AEM development to simultaneously consider ion conduction, stability, water sorption, and mechanical properties.

AEMs require a polymer chemistry of dual functionality, often achieved using copolymers, where one section of the polymer is ionic and hydrophilic to promote ion conduction while the other is hydrophobic to maintain the solid integrity of the membrane. Block copolymers are of particular interest due to their ability to phase separate into organized morphologies that generate well-defined ion conduction paths. Polystyrene based diblocks have been synthesized previously that organized into various morphologies including spheres, cylinders, and lamellae depending on the ratio of the polymer blocks.[12] While polystyrene based diblocks have showed good ionic conductivity and ordered morphologies,[12,13] the high $\mathrm{T}_{\mathrm{g}}$ polystyrene in an cationic membrane results in stiff, brittle films that do not have adequate mechanical durability for use in electrochemical devices. Replacing the hydrophobic block with a rubbery polymer, such as poly(methyl butylene), produced films with better elasticity and flexibility.[14] Similarly, polyethylene has been incorporated in AEMs. Ring-opening metathesis polymerization of ammonium functionalized cyclic olefins produced crosslinked and noncrosslinked polyethylene copolymer AEMs with good conductivity and mechanical durability.[15,16] Polyethylene based AEMs with flexible ammonium groups in a crosslinked matrix synthesized by metallocene-mediated copolymerization displayed adequate swelling and exceptional conductivity, $75-120 \mathrm{mS} / \mathrm{cm}$.[17] Grafting vinylbenzyl chloride units on to polyethylene resin or free-standing films has generated AEMs with decent conductivity and chemical stability.[18,19] While copolymer and grafted polyethylene AEMs show promising 
performance, the cationic functionalities are of a random nature, and do not benefit from the well-defined morphologies produced in block copolymer systems. This work investigates a polyethylene-based diblock AEM that will combine organized polymer morphology and good mechanical properties.

Fuel cells operate in a dynamic environment in terms of temperature and humidity resulting in a range of hydration levels in AEMs. At high humidities, water is taken up by the polymer causing dimensional swelling of membranes.[20,21] Under dryer conditions, the membrane loses water causing film contraction and significant hygrothermal stresses in the polymer.[21,22] With repeated humidity cycling, these hygrothermal stresses can generate pinhole and cracks in the membrane that contribute to catastrophic failure.[21,23,24] AEMs must have adequate elasticity and elongation at dry conditions to accommodate for dimensional swelling without damaging the membrane or causing plastic deformation.[20] Limiting the dimensional swelling of an AEM will improve mechanical durability,[20] but the ionic nature of the polymer and the fact that water is required to facilitate ion conduction makes swelling inevitable. Functionalization of a polymer with cations reduces elasticity and elongation,[13] making it difficult to produce AEMs that maintain adequate mechanical durability. Additionally, water sorption in AEMs can severely soften and weaken AEMs when they are hydrated.[25] Producing AEMs that have sufficient elasticity and elongation at dry conditions and maintain adequate strength at hydrated conditions is a continued challenge. Characterization of mechanical properties over the complete range of operating temperatures and hydration levels is critical to the development of robust AEMs.

A polyethylene-b-poly(vinylbenzyl trimethylammonium) was synthesized by anionic polymerization and previously characterized in terms of basic morphology, conductivity, and 
mechanical properties as a function of block ratio.[26] This AEM polymer can be solution cast to produce large, thin films. In this study, a single block ratio was evaluated to determine mechanical properties as function of humidity and correlated to water content and ion conduction.

\section{Experimental}

The polyethylene-b-poly(vinylbenzyl bromide) (PE-b-PVBBr) polymer was synthesized as previously described.[26] Large area, $\sim 300 \mathrm{~cm}^{2}$, thin films, $10-15 \mu \mathrm{m}$ were fabricated and characterized with respect to ionic conductivity, water uptake, swelling, and mechanical properties.

\section{Membrane Fabrication}

For membrane casting the polymer was dissolved in xylene at a $10 \mathrm{wt} \%$ concentration, the solution was mixed at $90^{\circ} \mathrm{C}$ for $2 \mathrm{~h}$. An automatic film applicator (MTI Corporation's MSKAFA-III, Richmond, CA) with a micrometer adjustable blade was used to draw the polymer solution at a consistent speed and thickness. A temperature-controlled hotplate was placed over the existing vacuum chuck of the film applicator. A glass plate was positioned on the hotplate and heated to $80^{\circ} \mathrm{C}$. The micrometer adjustable blade was kept in an oven at $80^{\circ} \mathrm{C}$ until immediately prior to casting. The blade was removed from the oven, placed on the glass substrate, the hot polymer solution was poured in front of the blade, and the solution was drawn to a thin wet film. The blade was set to a gap height of 200 microns and drawn at a speed of 50 $\mathrm{mm} / \mathrm{s}$. After casting, the hotplate was kept at $80^{\circ} \mathrm{C}$ for $30 \mathrm{~min}$, after which the temperature control was turned off and the substrate allowed to cool. The film was allowed to dry overnight at room temperature in the fume hood. The next day, the polymer film was removed from the glass substrate. The film was further dried overnight in a vacuum oven at $80^{\circ} \mathrm{C}$ to remove residual solvent. Vinylbenzyl trimethylammonium cation functionalities were generated by 
soaking the film in $25 \mathrm{wt} \%$ trimethylamine solution at room temperature for 2 days. After functionalization the film was washed repeatedly to remove excess trimethylamine and dried overnight in a vacuum oven at $40^{\circ} \mathrm{C}$. Films were characterized in the bromide counter ion form to avoid conversion of hydroxide ions to a mixture of carbonates and hydroxide ions.

\section{Ion Exchange Capacity}

Ion exchange capacity (IEC), number of cations per mass of polymer, of the membranes was measured by Mohr titration. Films were converted to the chloride form by soaking in $1 \mathrm{M}$ $\mathrm{NaCl}$ for at least $48 \mathrm{~h}$, followed by rigorous washing in distilled water to remove excess salt and drying in a vacuum oven. The chloride form films were soaked in $100 \mathrm{~mL}$ of $1 \mathrm{M} \mathrm{NaNO}_{3}$ for 48 h. Aliquots of the $\mathrm{NaNO}_{3}$ solution were titrated using a $\mathrm{AgNO}_{3}$ solution with a $\mathrm{K}_{2} \mathrm{CrO}_{4}$ indicator. The end of the titration was defined by the presence of permanent rust colored precipitates in solution.

\section{Ionic Conductivity}

In-plane ionic conductivity was measured by electrochemical impedance spectroscopy using a multichannel potentiostat (BioLogic VMP3) and a TestEquity environmental chamber. Impedance spectra were obtained over a frequency range of 1 to $10^{6} \mathrm{~Hz}$. Membrane resistance was determined by the low frequency intercept of Nyquist plot and membrane conductivity was calculated based on equation ( 1 )

$$
\sigma=\frac{\mathrm{l}}{\mathrm{R} \cdot \mathrm{t} \cdot \mathrm{w}}
$$

Where $\mathrm{R}$ is the membrane resistance, $\mathrm{l}$ is the distance between electrodes, and $\mathrm{t}$ and $\mathrm{w}$ are the thickness and width of the membrane sample. Conductivity was measured as a function of temperature between 50 and $90^{\circ} \mathrm{C}$, at $95 \%$ relative humidity, to determine the activation energy for ion conduction. Conductivity was also measured as a function of humidity between 30 and 
$90 \% \mathrm{RH}$, at $60^{\circ} \mathrm{C}$, to determine the effect of hydration on ion conduction. Conductivity was measured at $60^{\circ} \mathrm{C}$ starting at $30 \% \mathrm{RH}$, increasing humidity in $10 \% \mathrm{RH}$ steps, up to $90 \% \mathrm{RH}$ and back down to $30 \%$ RH. Conductivity was measured for $30 \mathrm{~min}$ at each relative humidity set point after a steady RH was achieved.

\section{Water Uptake}

Water uptake was measured gravimetrically from liquid water at room temperature and from water vapor at $60^{\circ} \mathrm{C}$. Liquid water uptake was measured by weighing samples dried overnight in a vacuum oven at $40^{\circ} \mathrm{C}$ compared to samples soaked in liquid water for $24 \mathrm{~h}$. Soaked samples were blotted to remove surface water and weighed immediate to prevent dehydration. All samples were weighed three times and averaged. Vapor water uptake was measured by using dynamic vapor sorption apparatus (SMS DVS Advantage 1, Allentown, PA). Samples were dried at a set point $0 \% \mathrm{RH}$ (actual \% RH was less than $1.7 \%$ ) for 20 minutes to obtain the dry weight of the sample. After the initial drying period, the sample was equilibrated at $10 \% \mathrm{RH}$ for 20 minutes to obtain a starting hydration level similar to mechanical testing. Following the equilibration period, humidity was ramped at $0.25 \% \mathrm{RH} / \mathrm{min}$ while the DVS instrument measures the gravimetric change in mass. The ramp rate was chosen to match dynamic mechanical experiments. Water uptake is calculated based on equation ( 2 )

$$
\mathrm{WU}=\frac{\mathrm{m}_{\% \mathrm{RH}}-\mathrm{m}_{\mathrm{dry}}}{\mathrm{m}_{\mathrm{dry}}} \times 100
$$

where $\mathrm{m}_{\% \mathrm{RH}}$ is the mass at the given relative humidity and $\mathrm{m}_{\mathrm{dry}}$ is the dry sample weight. If the IEC is known then the number of waters per cation, $\lambda$, can be calculated with equation ( 3 )

$$
\lambda=\frac{\mathrm{WU}}{\mathrm{m}_{\mathrm{H}_{2} \mathrm{O}} \cdot \mathrm{IEC}}
$$

where $\mathrm{m}_{\mathrm{H} 2 \mathrm{O}}$ is the molar mass of water and IEC is the ion exchange capacity of the film. 


\section{Dimensional Swelling}

Dimensional swelling due to water sorption was characterized by measuring film dimensions in the dry and liquid water soaked state. Membranes were dried overnight in a $40^{\circ} \mathrm{C}$ vacuum oven and measured in terms of width, length, and thickness. Width and length measurements were performed using a Marathon electronic digital caliper (0-150 mm, with 0.01 $\mathrm{mm}$ accuracy). Thickness measurements were made using a Marathon electronic digital micrometer (0-25 mm, with $0.002 \mathrm{~mm}$ accuracy). All measurements were repeated at least three times for each dimension. Samples were soaked in liquid water for $24 \mathrm{~h}$ in liquid water at room temperature. Samples were removed from the water, blotted to remove surface water, and quickly measured. In-plane and through-plane swelling were calculated based on the dimensional changes between the dry and wet states.

\section{Small Angle X-ray Scattering}

Small angle x-ray scattering experiments were performed at the X-ray Sciences Division, beamline 12-ID-B, at the Advanced Photon Source at Argonne National Laboratory. Measurements were taken in a transmission geometry using a Pilatus 2M SAXS detector. Typical acquisition time was $1 \mathrm{~s}$ with a beam energy of $12 \mathrm{keV}$ and an incoming wavelength of 1 Å. A custom-built sample oven was used to control sample temperature and humidity, details for this setup are available in literature. Samples were loaded in the sample chamber allowed to dry, at $<5 \% \mathrm{RH}$, for 40 minutes before initial scattering acquisition. Humidity was increased in steps

of $25 \% \mathrm{RH}$ and holding at each humidity for 40 minutes before scattering. In the last step samples were equilibrated at saturated conditions, $>90 \% \mathrm{RH}$, for 60 minutes before scattering. Samples had no indication of anisotropy, so scattering was radially averaged to obtain intensity vs. scattering vector data. 
Small angle x-ray scattering experiments of samples in a liquid water environment were performed on beamline 7.3.3 of the Advanced Light Source (ALS) at Lawrence Berkeley National Laboratory (LBNL). Scattering patterns were collected using a 2D Dectris Pilatus 2M CCD detector $(172 \mu \mathrm{m} \times 172 \mu \mathrm{m}$ pixel size $)$ with a wavelength of $\lambda=0.124 \mathrm{~nm}$ and a monochromator energy resolution of E/dE of 100. SAXS experiments for liquid-equilibrated samples were done in-situ using custom-designed temperature-controlled solution cells with $\mathrm{X}$ ray transparent Kapton ${ }^{\mathrm{TM}}$ windows. Samples were placed in the solution cells with liquid water and equilibrated for two hours at $25^{\circ} \mathrm{C}$. Then, the cell was heated to $60^{\circ} \mathrm{C}$ and SAXS patterns were collected. The two-dimensional scattering patterns were radially averaged to 1-D intensity profiles.

\section{Infrared Spectroscopy}

An ATR-FTIR spectroscopy (Nicolet Nexus ${ }^{\mathrm{TM}} 470$ FTIR) with heated zinc selenide (ZnSe) crystal ATR accessory (Specac, Inc.) was used to study the sorption and desorption process of water vapor in the membrane. A liquid nitrogen cooled mercury-cadmium-telluride detector was used to improve the measurement accuracy. All spectra were collected with a 256 scans and resolution of $4 \mathrm{~cm}^{-1}$. A common background collected at dry conditions was subtracted from all spectra. IR spectra were collected at $30^{\circ} \mathrm{C}$ as a function of $\mathrm{RH}$ in $10 \% \mathrm{RH}$ steps. The membrane was equilibrated for 40 minutes at each RH step. The total constant $200 \mathrm{sccm}$ of dry and wet nitrogen gas flow rate was controlled using mass flow controllers (MKS). The RH and temperature was controlled using a custom built system for the ATR-FTIR spectroscopy, details available in literature.[27] The IR spectra were smoothened for atmospheric $\mathrm{CO}_{2}$ suppression and corrected to a common baseline. 


\section{Extensional tests}

Extensional mechanical testing was performed using a Sentmanat Extension Rheometer (SER) (Xpansion Instruments, Tallmadge, OH) fixture on an ARES G2 rheometer (TA Instruments, New Castle, DE). The SER has two counter-rotating drums; films are suspended between drums and stretched to failure. The SER fixture is typically used to measure extensional viscosity of polymer melts, but has also been shown to accurately measure tensile properties of solid polymers.[25,28] The SER drums were modified to have screw down pins that would hold thin samples, a small amount of silicon rubber on the inside of the pin prevented film slip and generation of pinch points that would cause premature failure.[29] Double sided tape was also placed on the drum surface to aid sample loading and further prevent film slip. Films were tested at Hencky strain rates that correspond to ASTM D882-12, for tensile testing of thin plastic sheeting, but rates were modified to account for the constant sample loading distance inherent to the SER fixture. Hencky strain rate is determined by final elongation and due to all samples having elongations larger than $100 \%$ a strain rate of $0.33 \mathrm{~s}^{-1}$ was used for all testing.

Samples were tested under dry and fully saturated air conditions at $60^{\circ} \mathrm{C}$. A custom-built sample chamber was used to control temperature and humidity simultaneously.[29] The electrical heaters control temperature and a combination of dry and wet gas lines supply humidified gas to the chamber. Temperature and humidity probes (Vaisala HMT 337) provided real time feedback of sample conditions to control gas flows and temperature set points.

\section{Dynamic Mechanical Analysis}

Dynamic mechanical testing was performed while ramping temperature, at constant dry or saturated relative humidity, and by ramping humidity, at constant temperature, to distinguish mechanical transitions due to temperature and hydration level. DMA test were performed on the 
ARES G2 rheometer with the film/fiber tension geometry. The unique Force Rebalance Transducer (FRT) of the ARES G2 allows small amplitude, up to 50 micron, oscillatory measurements in the axial direction. Temperature was ramped at a rate of $0.5^{\circ} \mathrm{C} / \mathrm{min}$ from $30^{\circ} \mathrm{C}$ to $90^{\circ} \mathrm{C}$, up and down for one complete cycle. At dry conditions, samples were loaded at a $5 \mathrm{~mm}$ starting gap and had an oscillatory strain of $0.1 \%$ at a frequency of $1 \mathrm{~Hz}$. Dry tests used only dry gas flow and measured relative humidity was less than $10 \% \mathrm{RH}$ over the entire temperature range. Due to reduced sample stiffness at hydrated conditions, saturated tests were loaded at a starting gap height of $1 \mathrm{~mm}$ and had an oscillatory strain of $0.5 \%$ at a frequency of $1 \mathrm{~Hz}$. Saturated relative humidity tests utilized $4700 \mathrm{sccm}$ wet gas and $300 \mathrm{sccm}$ dry gas flow and had measured relative humidities above $85 \% \mathrm{RH}$ over the entire temperature range.

Tests ramping humidity were performed at a ramp rate of $0.25 \% \mathrm{RH} / \mathrm{min}$ from 10 to $90 \% \mathrm{RH}$, up and down for two complete cycles. The sample was maintained at $90 \% \mathrm{RH}$ for $1 \mathrm{~h}$ after the ramp up in humidity to ensure the sample was fully saturated before ramping humidity down. Humidity ramp tests were loaded at a starting gap height of $1 \mathrm{~mm}$ and had an oscillatory strain of $0.5 \%$ at $1 \mathrm{~Hz}$. All tests had a minimum axial force setting of $0.01 \mathrm{~N}$ and were set to maintain the axial force $30 \%$ higher than the oscillatory force on the sample. Sample tension (axial force) was maintained by automatic adjustment of the gap height, which caused sample elongation with increased temperature or humidity. Hydrated tests (temperature and humidity ramps) had total sample elongations up to $35 \%$, which was within the elastic region based on extensional testing.

\section{Results}

Casting the PE-b-PVBBr from xylene using the automatic film applicator resulted in large, $\sim 300 \mathrm{~cm}^{2}$, flexible films with a consistent thickness of 10-15 $\mu \mathrm{m}$ (Figure 1). 
Functionalization of the polymer with vinylbenzyl trimethylammonium cations was confirmed by titration. The theoretical IEC of the brominated polymer was $1.63 \mathrm{mmol} / \mathrm{g}$ based on the ${ }^{1} \mathrm{H}$ NMR spectra. The titrated IEC of the PE-b-PVBTMA was $1.21 \pm 0.08 \mathrm{mmol} / \mathrm{g}$ corresponding to a $74 \%$ conversion of brominated sites. The incomplete conversion of brominated sites to cations may be a result of low dimensional swelling (discussed later) of these films that would restrict transport of the trimethylamine into the polymer.

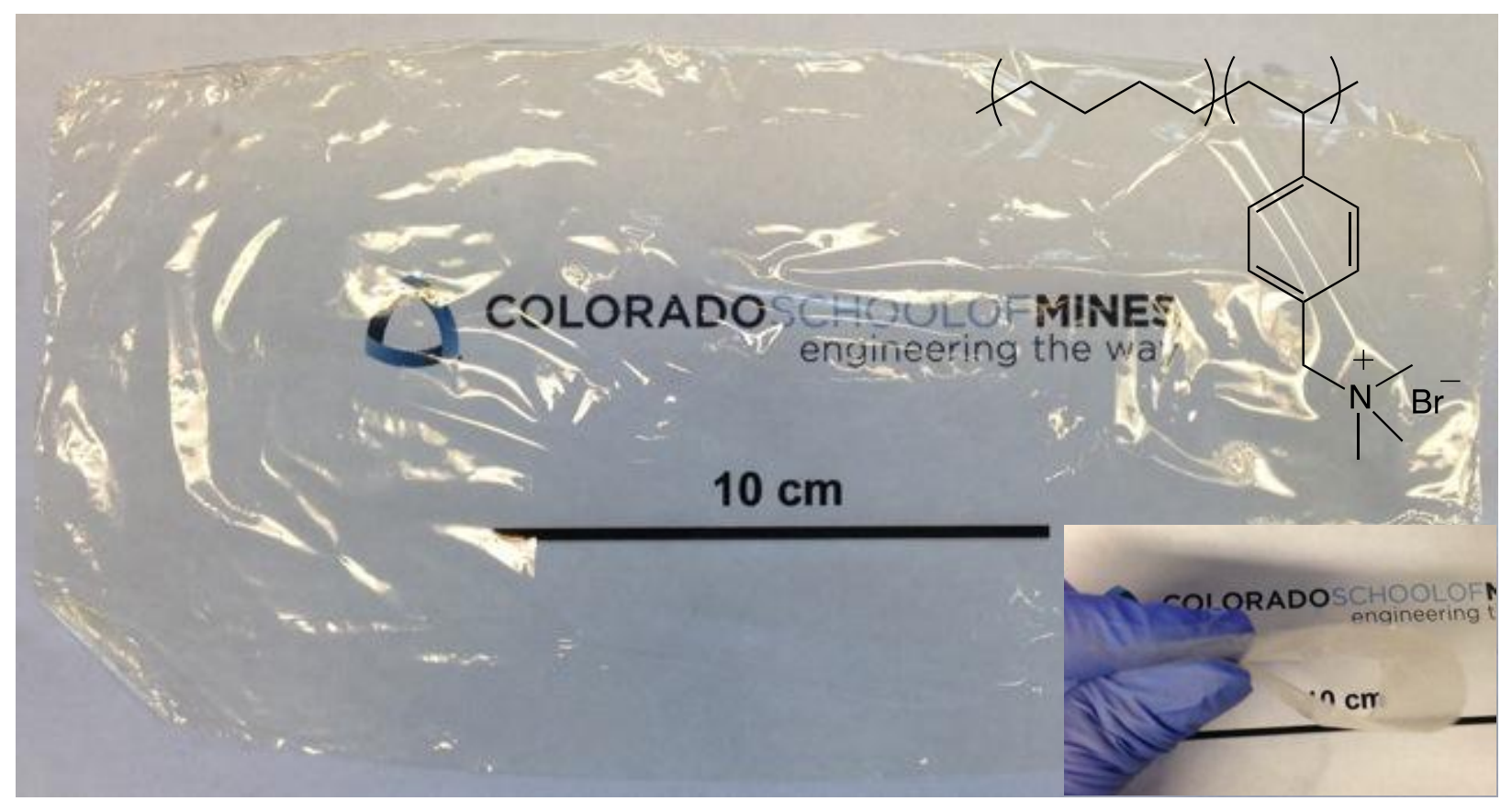

Figure 1: Photograph of PE-b-PVBTMA[Br] film after casting and functionalization. Film was pliable as shown by the folded film in the right lower inset.

Ionic conductivity of the PE-b-PVBTMA polymer in the bromide counter ion form was measured as a function of temperature at saturated conditions $(95 \% \mathrm{RH})$. Conductivity ranged from $5 \mathrm{mS} / \mathrm{cm}$ at $50^{\circ} \mathrm{C}$ to $15 \mathrm{mS} / \mathrm{cm}$ at $90^{\circ} \mathrm{C}$ and had an $\mathrm{E}_{\mathrm{a}}$ of $27 \mathrm{~kJ} / \mathrm{mol}$ based on an Arrhenius fit (Figure 2). These conductivities are similar to other AEMs with similar IECs.[12,30,31] The activation energy of the PE-b-PVBTMA membrane is higher than standard PEMs[32] and similar to slightly higher than AEMs.[30,33] 


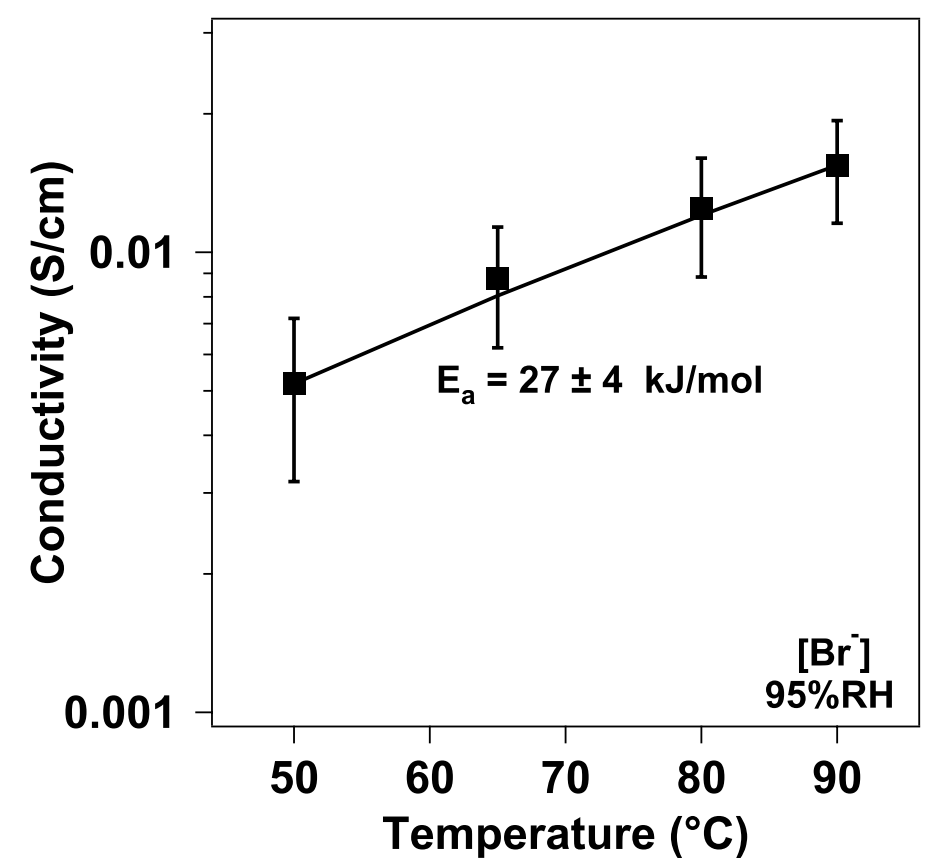

Figure 2: Ionic conductivity of the PE-b-PVBTMA[Br] polymer at $95 \% \mathrm{RH}$.

Liquid water uptake and swelling were measured to determine dimensional stability. Water uptake was relatively low for the PE-b-PVBTMA at $17 \pm 5 \%$, corresponding to a lambda value of $8 \pm 2$. This water uptake is smaller than most other AEMs,[34-36] due in part to its relatively low IEC. The low water uptake results in low dimensional swelling of the film. Dimensional swelling was $8 \pm 3 \%$ in the in-plane direction, and $5 \pm 2 \%$ in the through-plane direction. A low level of dimensional swelling is beneficial to prevent significant hygrothermal stresses due to elongation and contraction of the membrane during humidity changes and reducing the chance of delamination or cracking of catalyst layers in the stack.

Small angle x-ray scattering was performed to identify nanometer scale phase separation and organization in the membrane (Figure 3). The scattering of the PE-b-PVBTMA[Br] at dry and $90 \% \mathrm{RH}$ conditions exhibited a first order peak at $\mathrm{q}^{*}=0.146 \mathrm{~nm}^{-1}$, that corresponds to a dspacing of $43 \mathrm{~nm}$, and secondary shoulder at $\mathrm{q} \sim 0.43 \mathrm{~nm}^{-1}$, approximately three times $\mathrm{q}^{*}$. No distinguishable changes in scattering pattern were observed from dry to saturated gas conditions, 
other than a slight increase in intensity in the low q range. However, the first order peak shifted to lower q when the sample was soaked in liquid water. A first order peak in the liquid equilibrated sample at $\mathrm{q}^{*}=0.112 \mathrm{~nm}^{-1}$ corresponded to a d-spacing of $56 \mathrm{~nm}$, and a secondary shoulder at $\mathrm{q} \sim 0.33$ maintained the $3 \mathrm{q}^{*}$ ratio seen in the humidified sample. While the scattering pattern of the PE-b-PVBTMA[Br] suggested nanometer scale phase separation, the broad nature of the scattering features prevented specific characterization of copolymer morphology. The SAXS patterns suggested that the membrane has no dimensional change on the nanometer scale across the entire range of humidified gas conditions, but liquid water uptake causes a $13 \mathrm{~nm}$ increase in domain size.

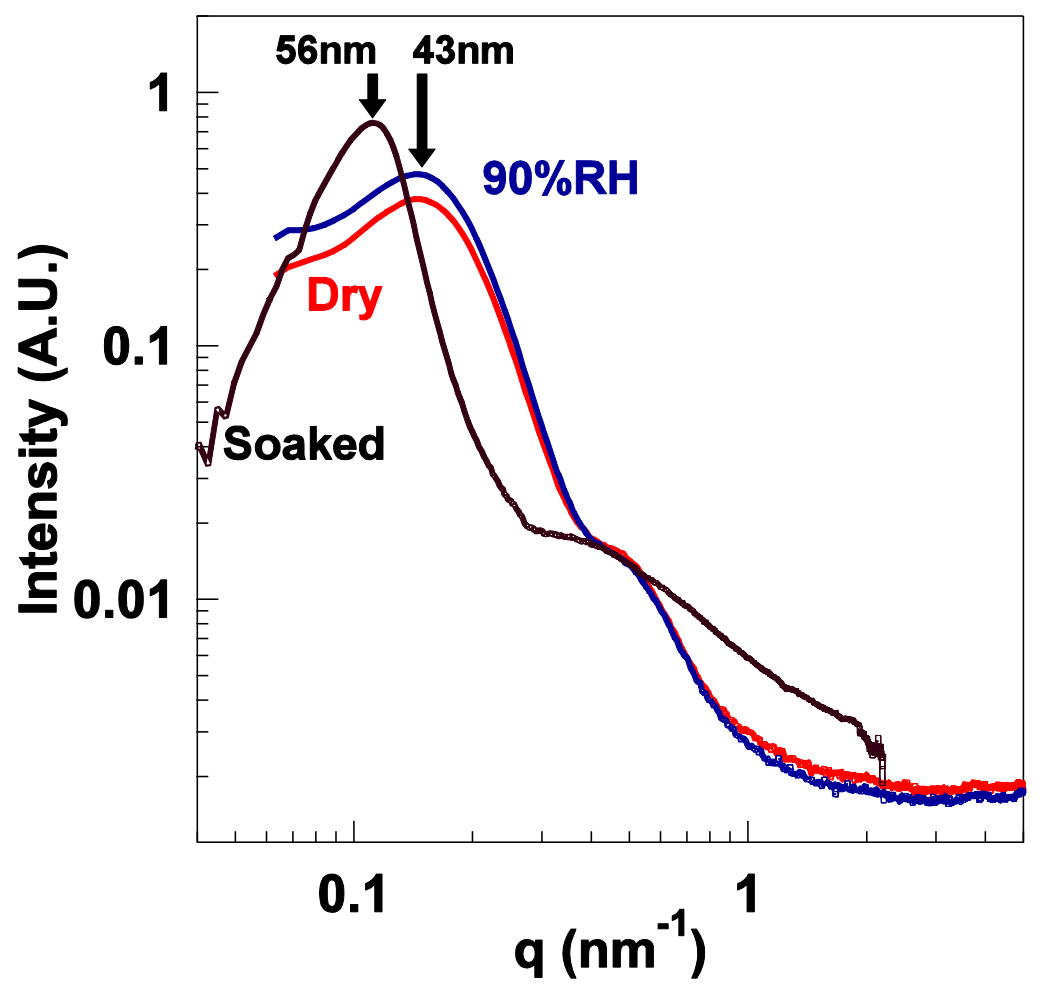

Figure 3: SAXS scattering patterns of the PE-b-PVBTMA[Br] membrane at dry $(<5 \% \mathrm{RH})$, $90 \% \mathrm{RH}$, and liquid soaked conditions. There is a first order scattering peak corresponding to a dspacing of $43 \mathrm{~nm}$ for the dry and $90 \% \mathrm{RH}$ conditions that shifts to $56 \mathrm{~nm}$ in the liquid soaked condition

Extensional tests were performed to measure tensile properties of the PE-bPVBTMA[Br] films under dry and saturated gas conditions at $60^{\circ} \mathrm{C}$ (Figure 4). When hydrated, 
water taken up by the polymer acts as a plasticizer, increasing elasticity and elongation and reducing strength. Water plasticization can be detrimental to the mechanical durability and performance of ion exchange membranes. Maintaining sufficient mechanical performance over a range of hydration levels is critical for long-term stability of AEMs. The PE-b-PVBTMA[Br] membrane had good strength at dry conditions, $28 \pm 4 \mathrm{MPa}$, and strength was only reduced by $29 \%$ to $20 \pm 4 \mathrm{MPa}$ when fully saturated. The strength of the PE-b-PVBTMA is lower than Nafion $^{\circledR},[29]$ but better than many AEMs, $[9,13,15,37]$ and the narrow change between dry to hydrated conditions is promising for stable performance in an electrochemical device. Elongation of the PE-b-PVBTMA[Br] film was $150 \pm 20 \%$ at dry conditions and $220 \pm 20 \%$ at saturated conditions. Elongation must be sufficient to accommodate dimensional swelling due to water uptake, and the elongation of the PE-b-PVBTMA is significantly larger than the dimensional swelling from liquid water, discussed previously. At dry conditions the PE-b-PVBTMA polymer has a Young's modulus of $210 \pm 30 \mathrm{MPa}$, similar to Nafion ${ }^{\circledR},[29]$ meaning the membrane is stiff enough to be dimensionally stable, but not brittle. However, when hydrated the membrane is severely softened, with the Young's modulus being reduced by $95 \%$ to $11 \pm 2 \mathrm{MPa}$. This reduction in modulus is significant and may be a concern for stable mechanical performance. The severe reduction of modulus between dry and hydrated states warranted further study by dynamic mechanical analysis. 


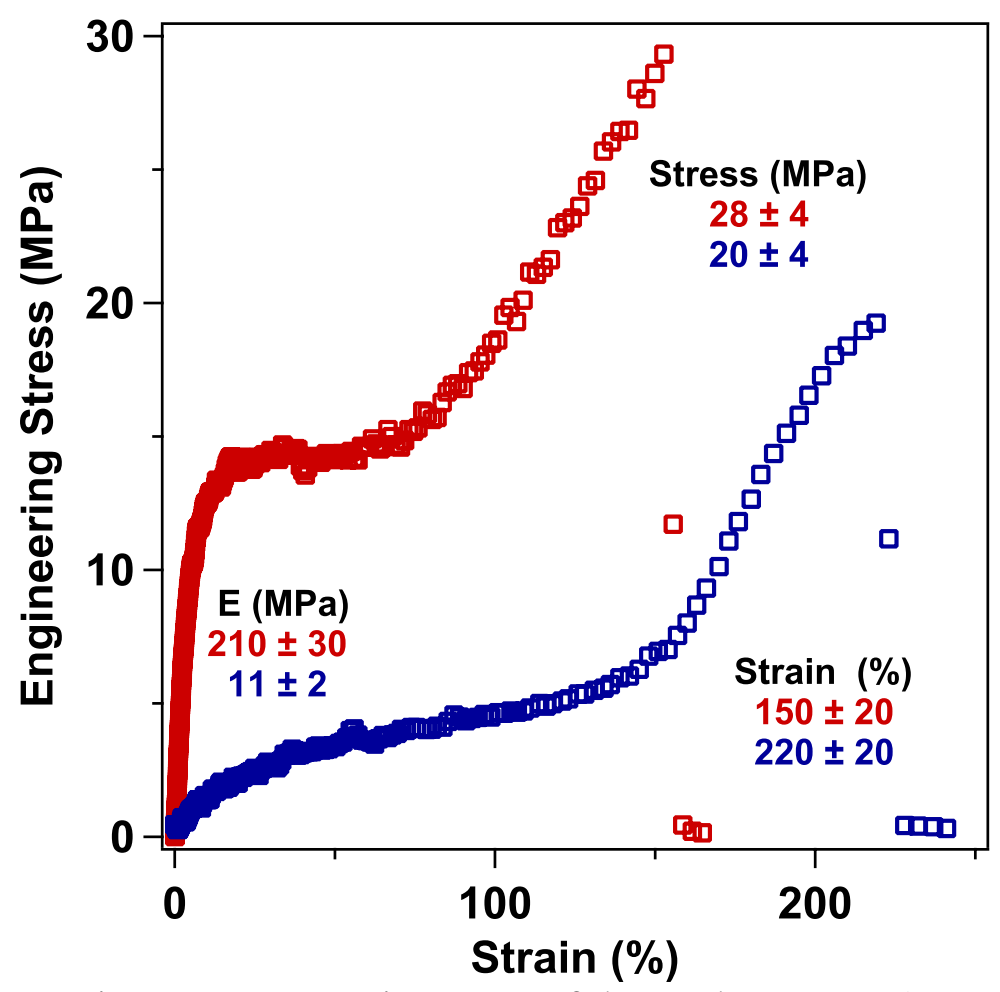

Figure 4: Representative stress vs. strain curves of the PE-b-PVBTMA[Br] films at dry (red) and 95\%RH (blue) conditions. Average tensile properties of Young's modulus (E), stress, and elongation are shown inside the figure.

Dynamic mechanical analysis was performed while ramping temperature under dry or saturated relative humidity conditions to identify thermomechanical transitions within the fuel cell operating range (Figure 5). At dry conditions, the storage modulus has a fairly narrow range varying from $420 \pm 120 \mathrm{MPa}$ at $30^{\circ} \mathrm{C}$ to $210 \pm 10 \mathrm{MPa}$ at $90^{\circ} \mathrm{C}$ and shows no hysteresis between the heating and cooling. While the dry storage modulus changed by about $50 \%$ between 30 $90^{\circ} \mathrm{C}$, under hydrated conditions the change in modulus was more significant ranging from $43 \pm$ $13 \mathrm{MPa}$ at $30^{\circ} \mathrm{C}$ to $6 \pm 1 \mathrm{MPa}$ at $90^{\circ} \mathrm{C}$. 


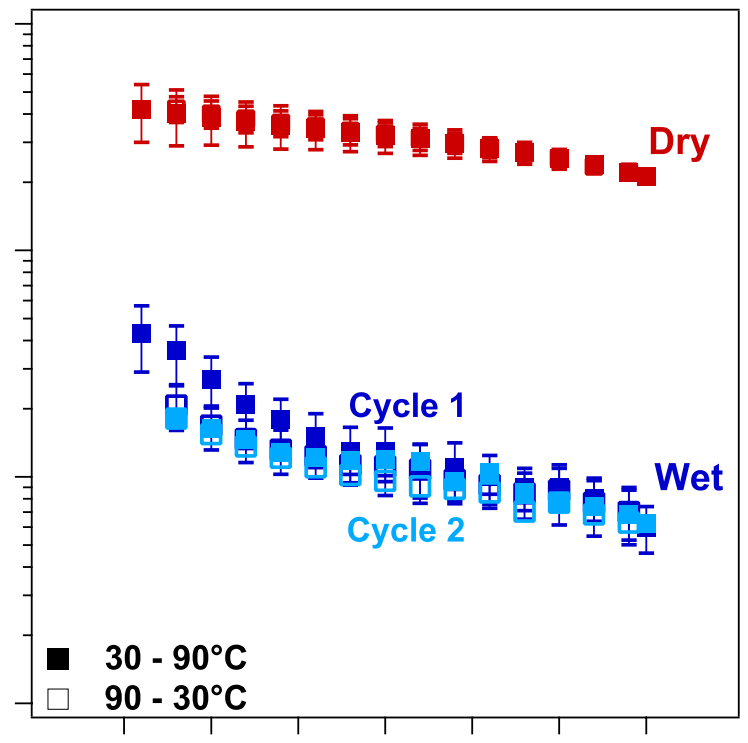

Figure 5: Storage modulus, measured by DMA, of the PE-b-PVBTMA[Br] membranes as a function of temperature under dry and saturated relative humidity conditions. Solid markers are during heating from $30-90^{\circ} \mathrm{C}$ and open markers are during cooling from $90-30^{\circ} \mathrm{C}$. The light blue data is the second cycle of heating and cooling for one sample at saturated conditions.

At hydrated conditions hysteresis in the storage modulus is observed. Upon cooling from $90^{\circ} \mathrm{C}$ to $30^{\circ} \mathrm{C}$, the storage modulus measured only $21 \pm 5 \mathrm{MPa}$, compared to $43 \pm 13 \mathrm{MPa}$ at the start of the test. This hysteresis could be due to different sorption kinetics during heating compared to cooling, incomplete saturation at the start of the test even after $1 \mathrm{~h}$ of equilibration, or higher sample elongation during the initial heating ramp to maintain sample tension. During the initial heating ramp, the sample elongates between $15-25 \%$ in order to maintain tension on the sample, and upon cooling the sample contracts but not fully, remaining $5-15 \%$ elongated. This hysteresis was further investigated by allowing the sample to undergo a second cycle of heating and cooling. The second cycle showed no hysteresis between heating and cooling steps, so it is likely that incomplete hydration at the start of the test resulted in higher moduli at low temperatures for the initial heating compared to cooling and subsequent cycle. While the storage moduli decreased with increasing temperature at both dry and hydrated conditions, no major 
mechanical transitions were observed over this range of temperatures, suggesting the large difference in moduli between dry and hydrated states is result of hydration alone.

Mechanical transitions related to hydration (humidity), hygromechanical, were analyzed by performing DMA while ramping humidity from 10 to $90 \% \mathrm{RH}$ and back to $10 \% \mathrm{RH}$, at a constant temperature (Figure 6). Humidity testing was initially performed at $60^{\circ} \mathrm{C}$ to match extensional testing. During humidification, the storage and loss moduli remained relatively steady until a sharp decrease in moduli between $55-75 \% \mathrm{RH}$, when both moduli are reduced by an order of magnitude. Upon dehumidification, the moduli transitioned back to its stiffened state, but the location for the transition was shifted to lower humidities (35-50\%RH). Returning to $10 \% \mathrm{RH}$ the storage modulus was larger, $350 \pm 4 \mathrm{MPa}$, than the initial value, $200 \pm 17 \mathrm{MPa}$, and the loss modulus decreased, $16.5 \pm 0.7 \mathrm{MPa}$, compared to the initial value of $24.5 \pm 0.7 \mathrm{MPa}$. Therefore, the modulus change due to hysteresis at $10 \% \mathrm{RH}$ (less than a factor of 2) is less significant than the order of magnitude change due to increasing humidity from 10 to $90 \% \mathrm{RH}$. This hysteresis of the moduli at dry conditions is most likely due to initial stretching of the film during the first humidification, because hysteresis was not seen in subsequent cycles. The samples were humidified and dehumidified a second time to determine further hysteresis of the membranes. The second cycle displayed the same softening transition during humidification and stiffening transition during dehumidification as the first cycle. At low humidities, the moduli values of the second cycle align with dehumidification values of the first cycle, further confirming that the low humidity hysteresis is due to initial sample elongation rather than differences of the kinetics of sorption and desorption. 


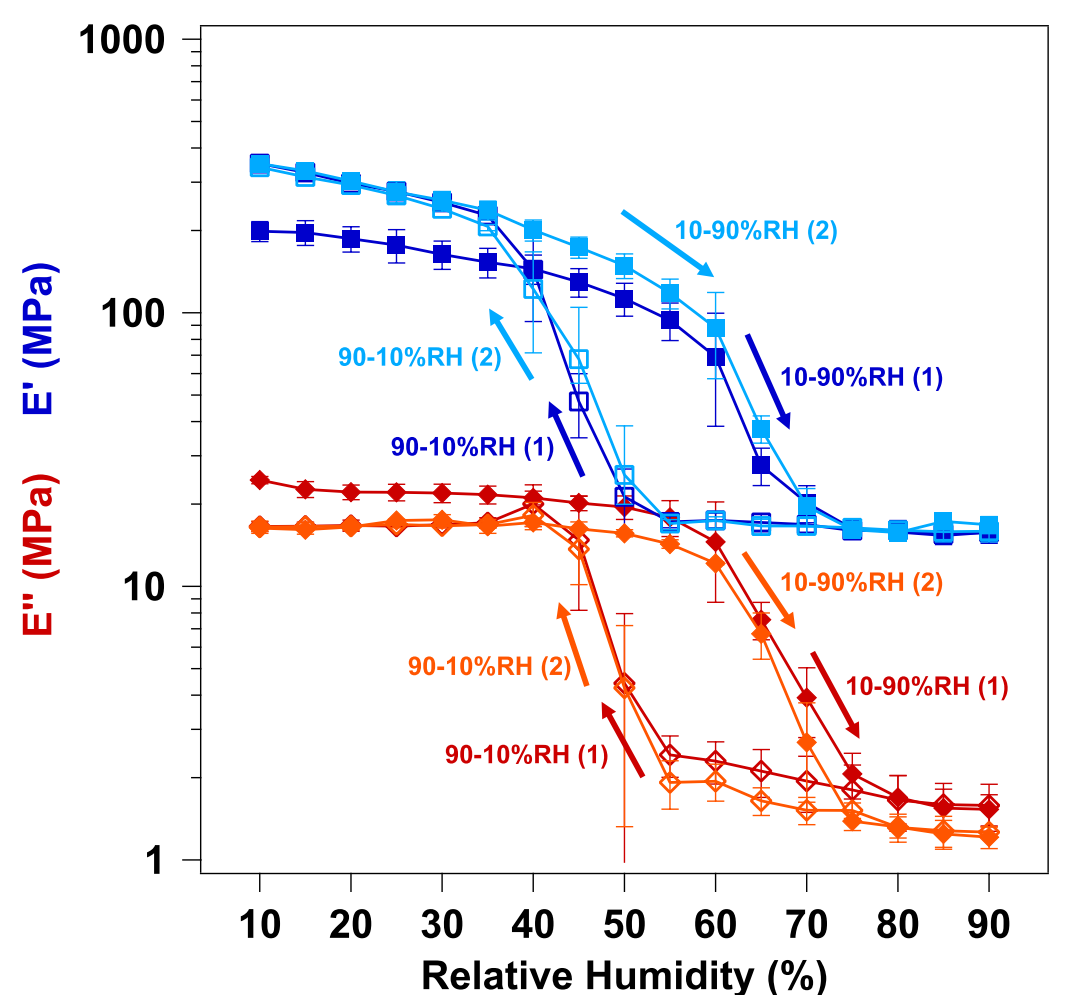

Figure 6: Storage (E') and loss (E') moduli of PE-b-PVBTMA[Br] as function of humidity. Solid markers are during humidification from $10-90 \% \mathrm{RH}$, open markers are during dehumidification from $90-10 \%$ RH. Cycle 1 is shown in dark blue (E') and red (E'), cycle 2 is shown in light blue (E') and orange (E").

The hygromechanical transition of the PE-b-PVBTMA membrane can be further confirmed by plotting Tan $\delta$ as a function of humidity (Figure 7). Error bars were removed from the Tan $\delta$ plot for clarity, but are included in the supplemental data. The onset of the E' drop can define the transition point in DMA, but a peak is Tan $\delta$ is often a clearer indication of the mechanical transition point.[38] Tan $\delta$ exhibits clear peaks at $65 \% \mathrm{RH}$ and $45 \% \mathrm{RH}$, for humidification and dehumidification, respectively. The magnitude of Tan $\delta$ decreases from the cycle 1 to cycle 2 , as a result of the moduli hysteresis, but the shape of the Tan $\delta$ curves remains consistent between cycles. 


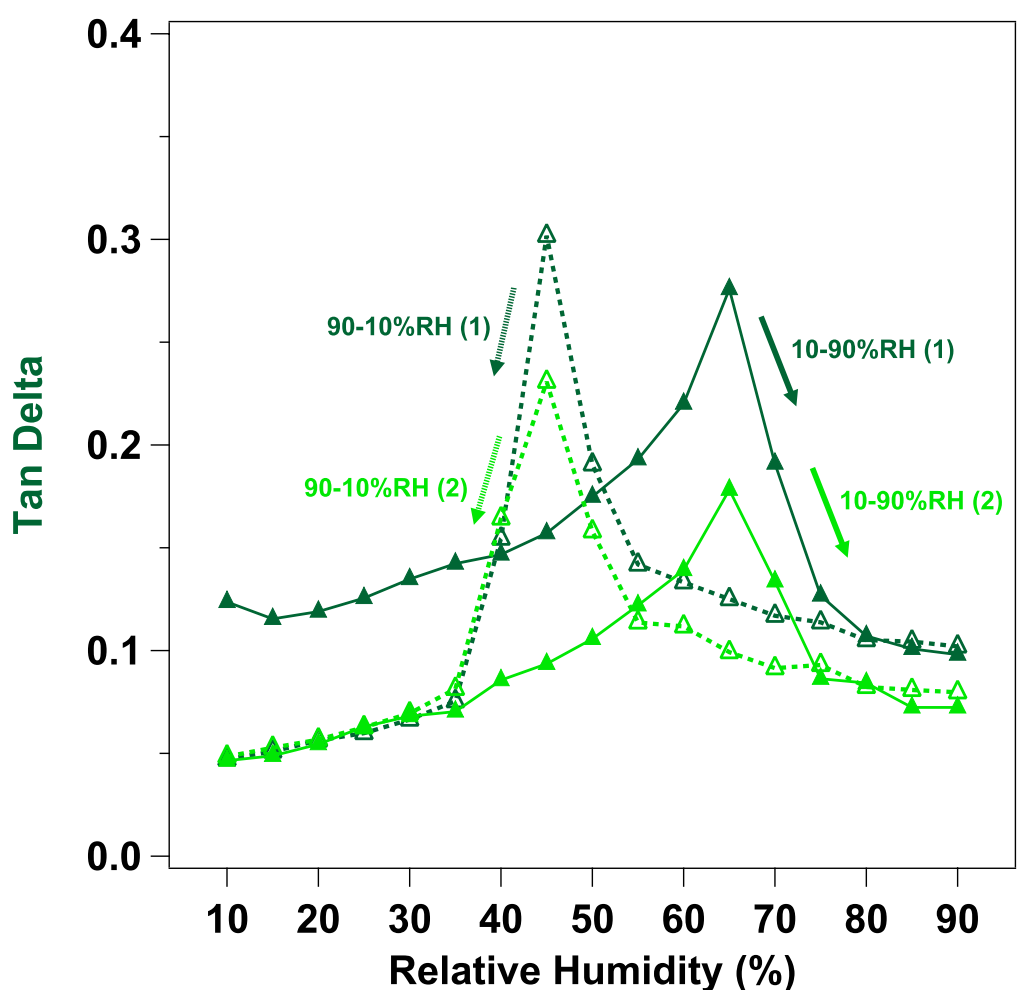

Figure 7: Tan $\delta$ vs. relative humidity, the solid markers are during humidification and open are markers are during dehumidification. Dark green corresponds to cycle 1 and light green to cycle 2 .

The hysteresis of the hygromechanical transition from humidification to dehumidification could be a result of different kinetics of water sorption compared to desorption. Polymer sorption and desorption kinetics were investigated by measuring gravimetric water uptake, using DVS, at the same conditions (ramp rate and cycle conditions) as the DMA testing. A small hysteresis in water uptake is measured during humidification compared to dehumidification (Figure 8), resulting in slightly differences in lambda values, up to 1.5 differences, between humidification and dehumidification for the same relative humidity value. 


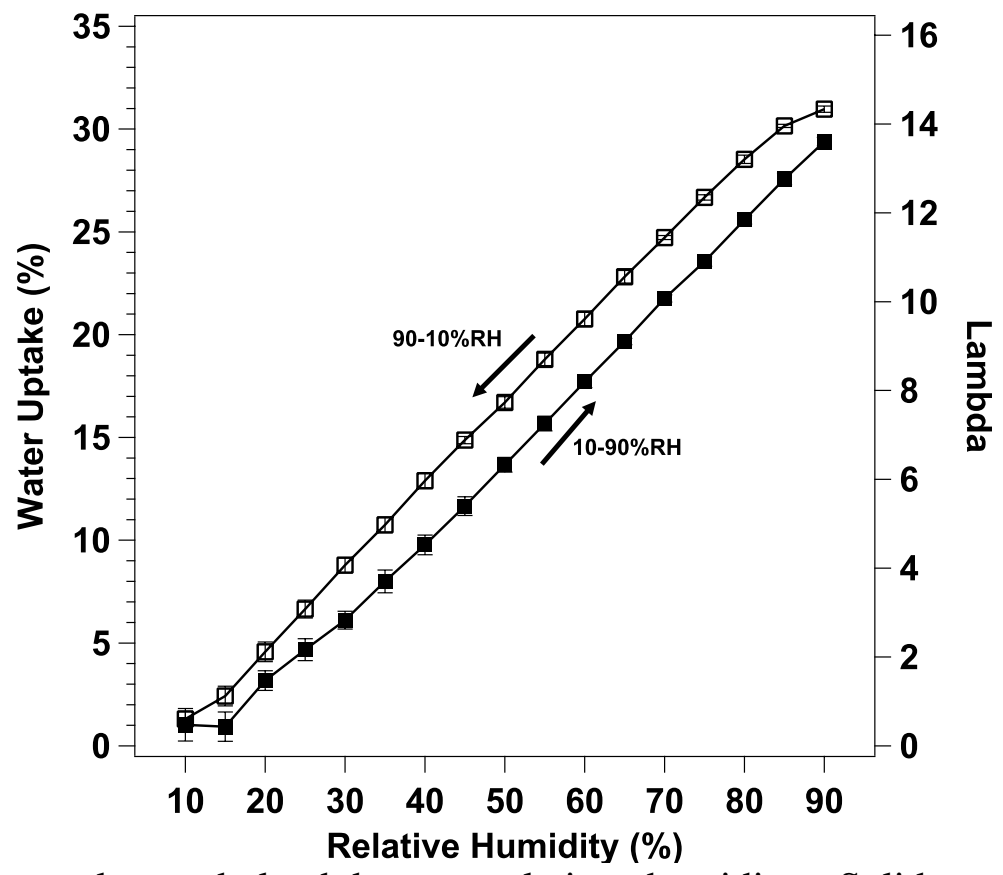

Figure 8: Water uptake and lambda vs. relative humidity. Solid markers are during humidification from $10-90 \% \mathrm{RH}$ and open markers are during dehumidification from 90 $10 \% \mathrm{RH}$. There was no significant difference from cycle 1 to cycle 2 so data from the two cycles was averaged together.

The DMA measurements can be normalized to lambda (water content) to eliminate the effect of sorption/desorption kinetics (Figure 9). Normalizing the measured moduli by lambda causes the hygromechanical transition window to narrow, however hysteresis is still clearly present from hydration to dehydration. Hysteresis when the moduli have been normalized to water content proves sorption/desorption kinetics are not solely responsible, rather the hysteresis is due to a different mechanical response during softening compared to stiffening. The hygromechanical transition occurs at lambda approximately equal to 9 during humidification, but the reverse transition occurs at a lower lambda value of about 7 during dehumidification. Membranes are softened at high hydrations, but there is a delay in stiffening while water content is being reduced. Delayed restiffening could significantly influence membrane performance as environmental conditions change within the fuel cell. 


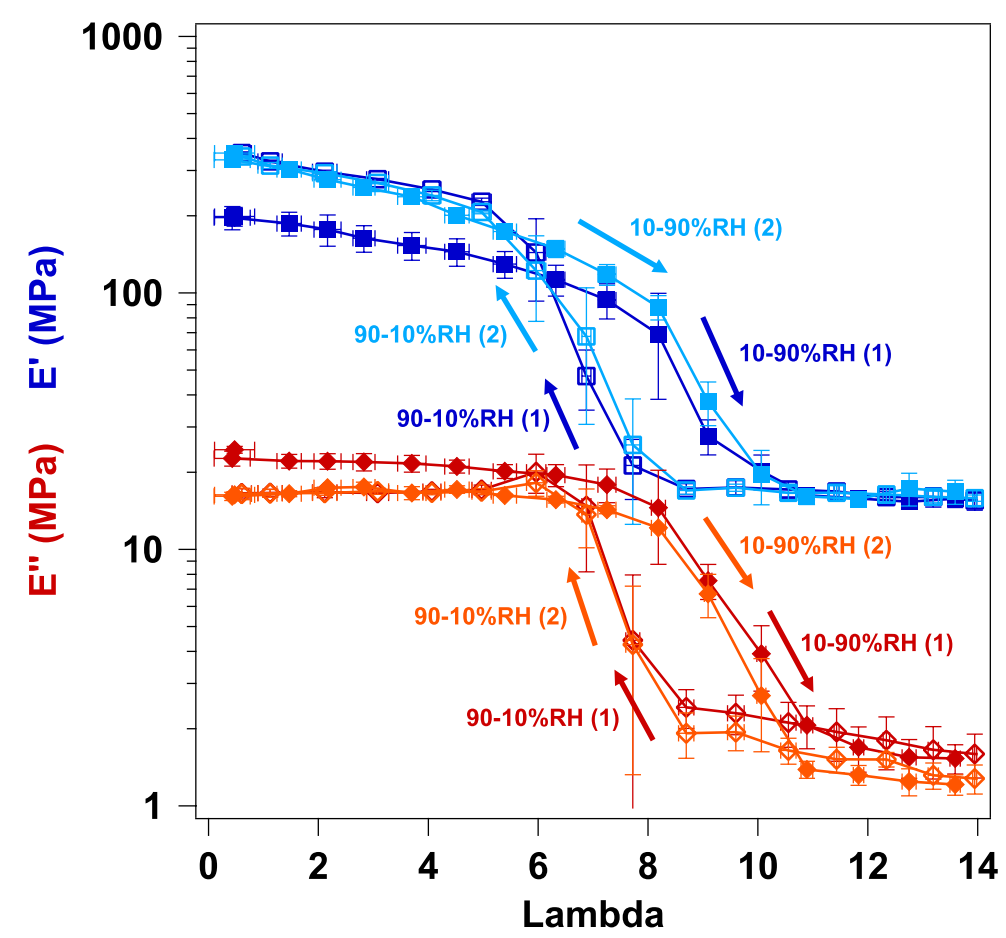

Figure 9: Storage (E') and loss (E') moduli as a function of lambda. Solid markers are during humidification from $10-90 \% \mathrm{RH}$, open markers are during dehumidification from $90-10 \% \mathrm{RH}$. Cycle 1 is shown in dark blue (E') and red (E'), cycle 2 is shown in light blue (E') and orange (E').

Hysteresis in the moduli remained even after normalization by lambda, proving that the hysteresis was not due to sorption kinetics alone, rather the interaction of water with the polymer differs between sorption and desorption affecting the mechanical properties. Infrared spectroscopy is helpful in examining water-polymer interactions through shifts in the infrared spectrum.[39] Infrared spectroscopy has been utilized to investigate the effects of water on ionic conductivity, transport, membrane morphology in Nafion ${ }^{\circledR} .[27,39-41]$ In AEMs, the molecular vibrational force constant of $\mathrm{C}-\mathrm{H}$ stretching bonds, corresponding to the quaternary trimethylammonium cation, is indicative of the bonding strength of water molecules associated with the cationic groups. Pandey et al describes the change in $-\mathrm{C}-\mathrm{H}$ infrared vibration frequency corresponding to [-N( $\left.\left(\mathrm{CH}_{3}\right)_{3}{ }^{+}\right]$group in hydrophilic region as a function of humidity.[27] 
IR spectra were obtained as a function of humidity (Figure 10), the regions of interest (O-H stretching, H-O-H bending, and $-\mathrm{C}-\mathrm{H}$ stretching present in $\left[-\mathrm{N}\left(\mathrm{CH}_{3}\right)_{3}{ }^{+}\right]$) were further analyzed.

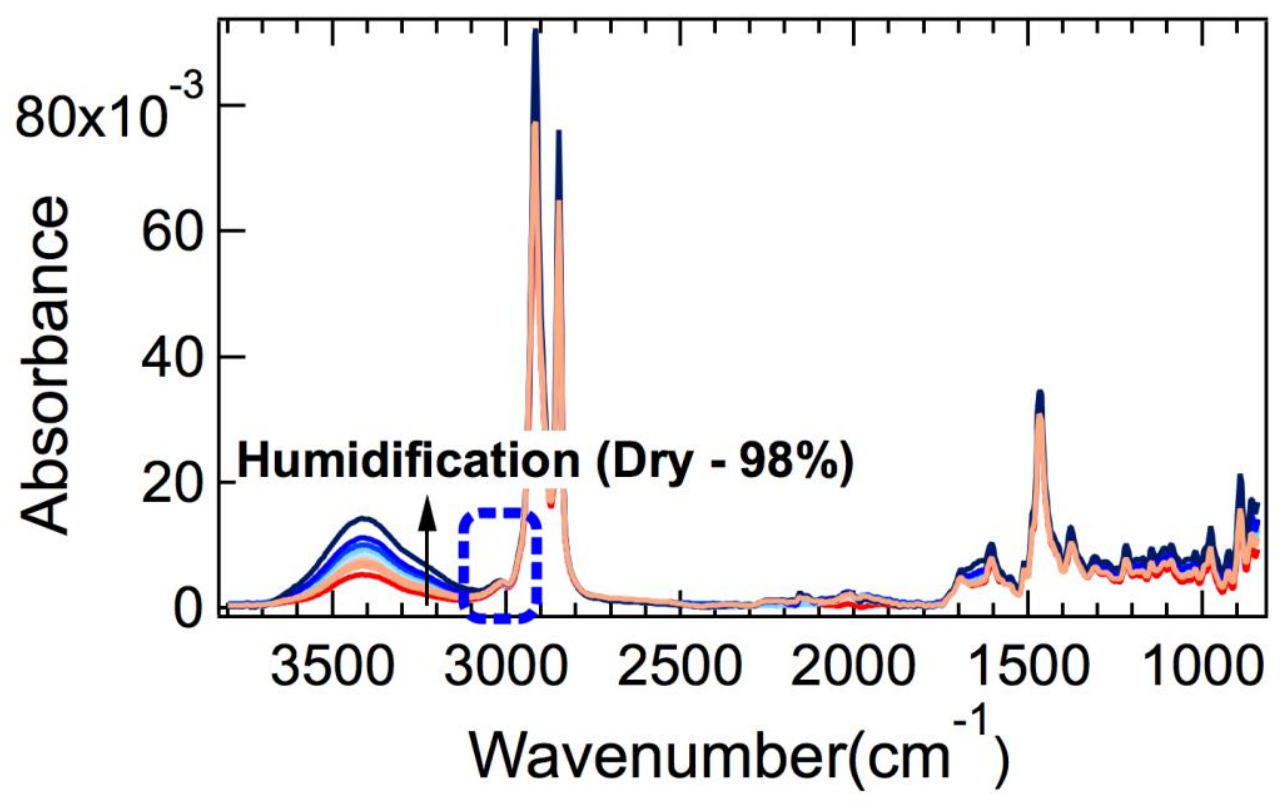

Figure 10: ATR-IR spectra collected on PE-b-PVBTMA membrane at $30^{\circ} \mathrm{C}$ as a function of RH between $0-98 \%$ in $10 \%$ RH steps. The blue dotted square is re-plotted in for further analysis.

The position of $\mathrm{C}-\mathrm{H}$ stretching $\left(\sim 3023 \mathrm{~cm}^{-1}\right)$ corresponds to $\left[-\mathrm{N}\left(\mathrm{CH}_{3}\right)_{3}{ }^{+}\right]$, experimentally and using density functional theory (DFT) method calculation.[27] Here, the frequency of $-\mathrm{C}-\mathrm{H}$ stretching that corresponds to $\left[-\mathrm{N}\left(\mathrm{CH}_{3}\right)_{3}{ }^{+}\right)$increased with the increase in the RH. The shift of the peak to higher frequency indicates the increasing force constant of the $-\mathrm{C}-\mathrm{H}$ bond.[27] An increase in $\mathrm{C}-\mathrm{H}$ bond strength with humidification and subsequent decrease in $\mathrm{C}-\mathrm{H}$ bond strength with dehumidification was observed for the PE-b-PVBMTA membrane. The shift in peak position of $-\mathrm{C}-\mathrm{H}$ stretch (Figure 11) as a function of $\mathrm{RH}$ indicated the increase in $-\mathrm{C}-\mathrm{H}$ molecular vibrational frequency. At $60 \% \mathrm{RH}$, the $-\mathrm{C}-\mathrm{H}$ stretching peak position was $3015 \mathrm{~cm}^{-1}$ and $3017 \mathrm{~cm}^{-1}$ for humidification and dehumidification, respectively. 


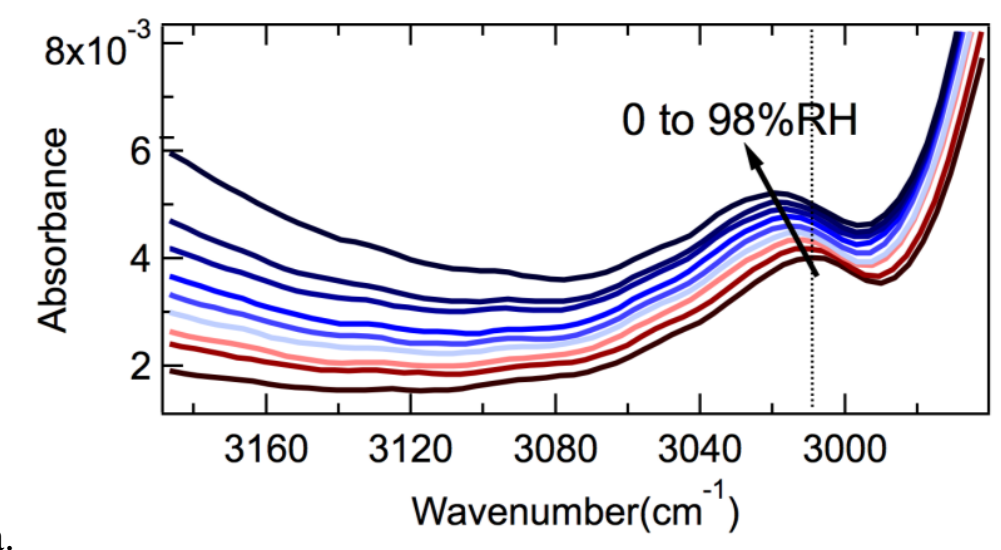

a.

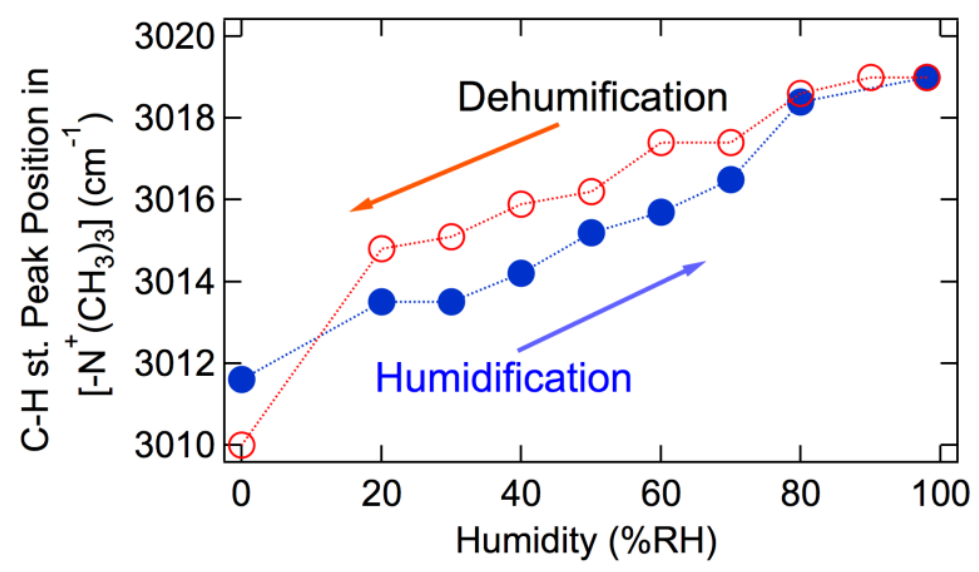

Figure 11: a.) -C-H stretching region of $\left[-\mathrm{N}\left(\mathrm{CH}_{3}\right)_{3}{ }^{+}\right]$of the PE-b-PVBTMA at $30^{\circ} \mathrm{C}$ as a function of relative humidity b.) The shift in $-\mathrm{C}-\mathrm{H}$ peak that corresponds to $\left[-\mathrm{N}\left(\mathrm{CH}_{3}\right)_{3}{ }^{+}\right]$showing different $-\mathrm{C}-\mathrm{H}$ bond strength for the humidification and dehumidification cycles.

As the force constant for the $-\mathrm{C}-\mathrm{H}$ vibration (frequency of $-\mathrm{C}-\mathrm{H}$ stretching vibration) increases, the force constant for water molecules bonded to the quaternary ammonium groups should decrease (and vice-versa). With the decrease in bonding force constant for water molecules with cationic group in the membrane, water is more freely available for morphological changes in the membrane. These less-bound water molecules are distributed in bulk polymer in the membrane reducing the storage and loss moduli as seen from the mechanical testing of these membranes. The presence of hysteresis in frequency peak position of $-\mathrm{C}-\mathrm{H}$ stretching that corresponds to $\left[-\mathrm{N}\left(\mathrm{CH}_{3}\right)_{3}{ }^{+}\right]$provides evidence that the water-polymer interaction is different at 
same RH during humidification vs. dehumidification and contributes to the hysteresis in mechanical properties discussed previously.

The effect of mechanical softening on ionic transport was investigated by measuring conductivity as a function of humidity. Conductivity must be measured at steady-state conditions, given the nature and duration of the measurement, so humidity could not be ramped at the same conditions as DMA testing. The conductivity measurement was not sensitive enough to detect any hysteresis between the increasing and decreasing humidity steps so all measurements were averaged for a given relative humidity. An increase in conductivity was measured following mechanical softening of the material at higher water contents (Figure 12). Conductivity is already highly dependent on water content,[12,42,43] but increased chain flexibility due to mechanical softening with hydration may also contribute to enhanced ion transport. The relationship between ion conduction and mechanical softening is important to understanding AEM performance, and could help identify operating conditions for maintaining membrane and device performance. It may be beneficial to fully saturate the membrane at the start of operation, to ensure mechanical softening, and then maintain humidity above the stiffening transition for sustained ion transport. 


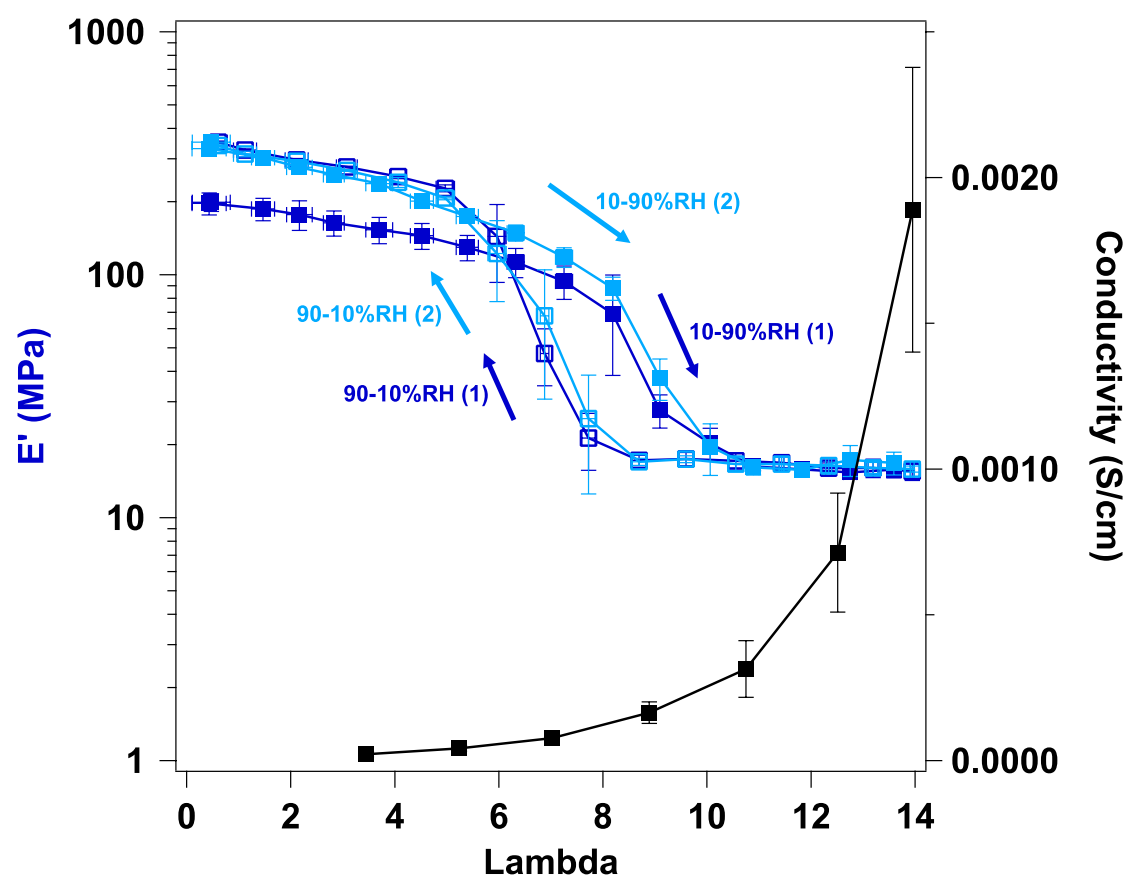

Figure 12: Storage modulus and ionic conductivity as a function of lambda.

In order to confirm that the hysteresis of the hygromechanical transitions was not exclusive to $60^{\circ} \mathrm{C}$, the humidity DMA tests were repeated at $40^{\circ} \mathrm{C}$ and $80^{\circ} \mathrm{C}$ (Figure 13). Error bars were removed from the data for clarity, but can be seen in supplemental data. At $40^{\circ} \mathrm{C}$, hygromechanical softening during humidification does not occur until very high humidities, between $70-85 \% \mathrm{RH}$, while the reverse transition during dehumidification is much lower, between $40-55 \% \mathrm{RH}$. Thus, reducing temperature to $40^{\circ} \mathrm{C}$ seems to increase the mechanical hysteresis between humidification and dehumidification. Alternatively, increasing the temperature to $80^{\circ} \mathrm{C}$ reduces hysteresis almost completely, so the transition occurs between 45 $55 \% \mathrm{RH}$ for both humidification and dehumidification. The modulus behavior at multiple temperatures could not be normalized by lambda, because dynamic vapor sorption was not available above $60^{\circ} \mathrm{C}$, but attempts were made to normalize the data using absolute humidity and enthalpy of the air. Normalization by absolute humidity and enthalpy shifted the transition curves, but no additional trends were distinguishable (see supplemental data). 
If ion transport is dependent on mechanical softening, the reduction of the transition point at higher temperatures suggests AEMs may successfully operate at lower humidity conditions at higher temperatures. While mechanical softening during humidification is dependent on temperature, mechanical stiffening, during dehumidification, is completed at the same relative humidity, $40 \% \mathrm{RH}$, regardless of temperature. The delay in mechanical stiffening may help maintain fuel cell performance, if the membrane is saturated initially (to induce softening), and then maintained at humidities above the stiffening transition. Identifying hygromechanical softening and hysteresis will help identify humidity conditions necessary to facilitate and maintain ion conduction in AEMs. 


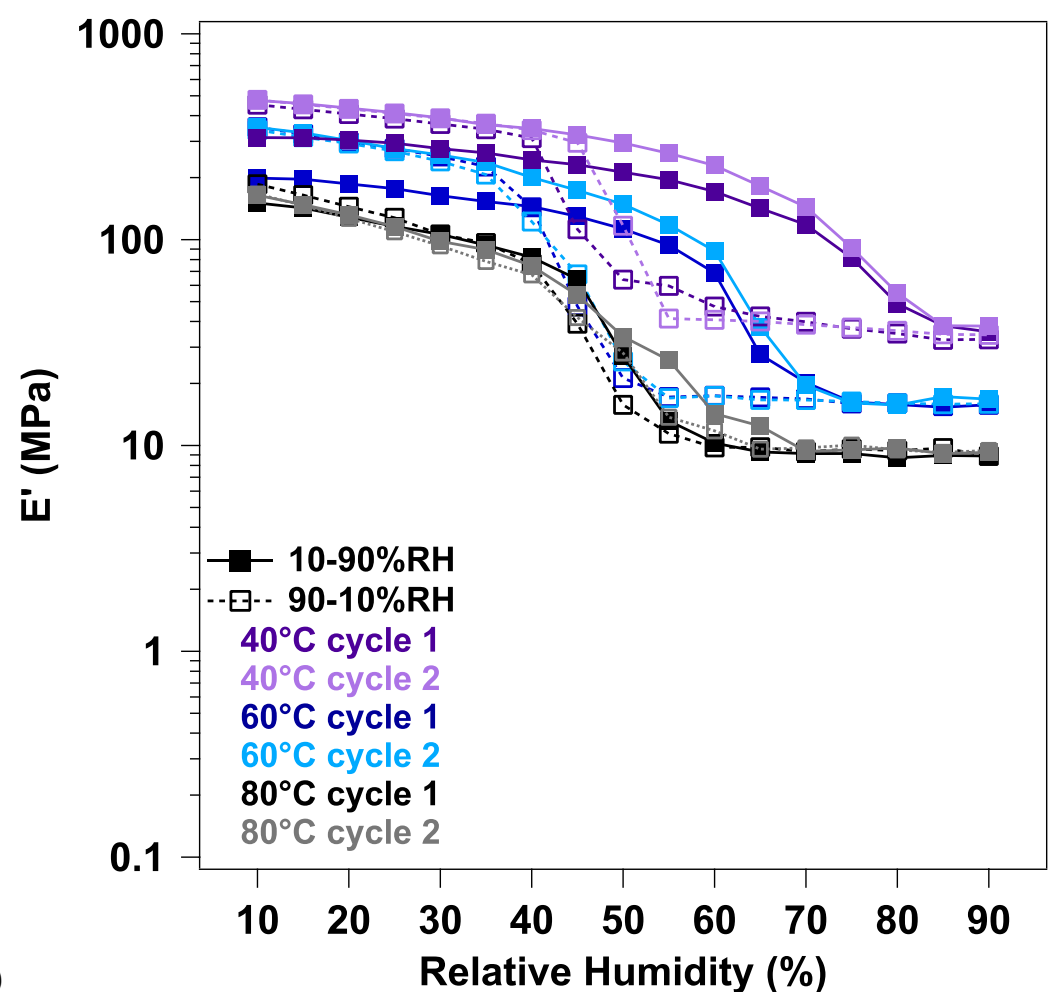

a)

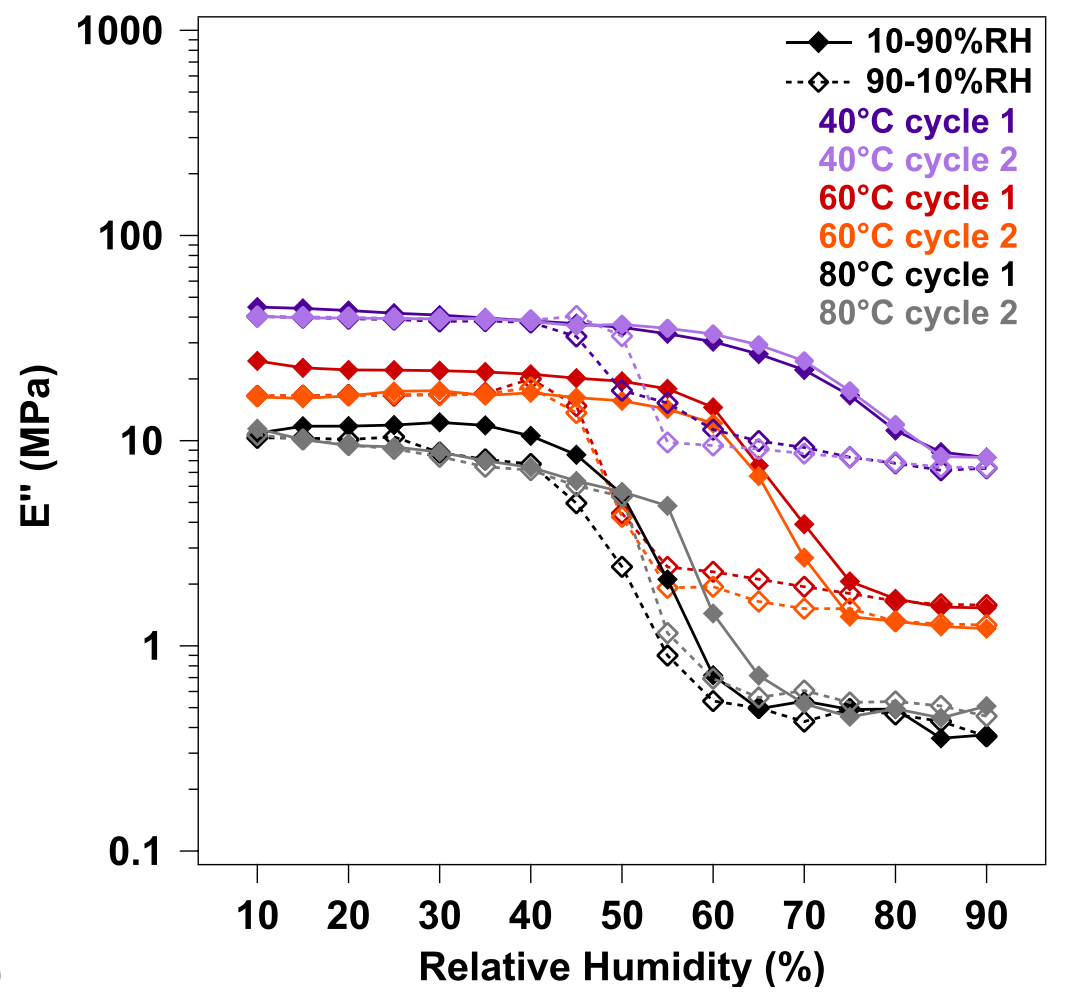

Figure 13: a) Storage modulus and b) loss modulus vs. relative humidity at $40^{\circ} \mathrm{C}$ (purple), $60^{\circ} \mathrm{C}$ (blue/red), and $80^{\circ} \mathrm{C}$ (black). 


\section{Conclusions}

The polyethylene-b-poly(vinylbenzyl trimethylammonium) is a promising AEM material that can be processed into thin, well-performing, stable membranes. The PE-b-PVBTMA membrane has relatively low water uptake and dimensional swelling, and good ionic conductivity. Extensional tests showed the membrane displayed good strength and elongations at both dry and hydrated conditions. However, significant softening of the membranes from dry to hydrated conditions warranted further investigation.

Dynamic mechanical analysis was performed while ramping humidity, keeping temperature constant at $60^{\circ} \mathrm{C}$. The storage and loss moduli displayed a sharp decrease during humidification, this transition was reversible between the dry and hydrated states, but the humidity at which the transition occurs displayed hysteresis between humidification and dehumidification. The dynamic moduli were normalized to water content, i.e., lambda, to eliminate the effects of sorption/desorption kinetics, but hysteresis between humidification and dehumidification remained. FTIR measurements suggested water-polymer interactions differed during humidification compared to dehumidification, these interactions would influence the hysteresis in mechanical properties observed.

Ionic conductivity was measured as a function of humidity, and the onset for increased conductivity corresponded to mechanical softening of the membrane. The correlation between conductivity and mechanical softening suggest that bulk mechanical properties could be used to determine the operational humidity levels required to facilitate sufficient ion transport. Mechanical testing at $40^{\circ} \mathrm{C}$ displayed a larger hysteresis between humidification and dehumidification, while there was no hysteresis at $80^{\circ} \mathrm{C}$, suggesting hysteresis is inversely proportional to temperature. Interestingly, while material softening during humidification was 
dependent on temperature, restiffening occurred around $45 \% \mathrm{RH}$, regardless of temperature. The relationship between ion conduction and mechanical softening is important to understanding AEM performance, and will lead to the development of robust, well-performing anion exchange membranes.

\section{Acknowledgments}

The authors thank the Army Research Office for support of this research under the MURI \#W911NF-10-1-0520 and DURIP \#W911NF- 11-1-0306. This research used resources of the Advanced Photon Source, a U.S. Department of Energy (DOE) Office of Science User Facility operated for the DOE Office of Science by Argonne National Laboratory under Contract No. DE-AC02-06CH11357.

\section{References}

[1] J.R. Varcoe, R.C.T. Slade, Prospects for Alkaline Anion-Exchange Membranes in Low Temperature Fuel Cells, Fuel Cells. 5 (2005) 187-200. doi:10.1002/fuce.200400045.

[2] M.A. Hickner, A.M. Herring, E.B. Coughlin, Anion exchange membranes: Current status and moving forward, J Polym Sci Pol Phys. 51 (2013) 1727-1735. doi:10.1002/polb.23395.

[3] J.R. Varcoe, P. Atanassov, D.R. Dekel, A.M. Herring, M.A. Hickner, P.A. Kohl, et al., Anion-exchange membranes in electrochemical energy systems, Energy Environ. Sci. 7 (2014) 3135-3191. doi:10.1039/C4EE01303D.

[4] G. Couture, A. Alaaeddine, F. Boschet, B. Ameduri, Polymeric materials as anionexchange membranes for alkaline fuel cells, Progress in Polymer Science. 36 (2011) 1521-1557. doi:10.1016/j.progpolymsci.2011.04.004.

[5] G.R. Merle, M. Wessling, K. Nijmeijer, Anion exchange membranes for alkaline fuel cells: A review, J Membrane Sci. 377 (2011) 1-35. doi:10.1016/j.memsci.2011.04.043.

[6] G.F. McLean, T. Niet, S. Prince-Richard, N. Djilali, An assessment of alkaline fuel cell technology, International Journal of Hydrogen Energy. 27 (2002) 507-526.

[7] J.B. Edson, C.S. Macomber, B.S. Pivovar, J.M. Boncella, Hydroxide based decomposition pathways of alkyltrimethylammonium cations, J Membrane Sci. 399-400 (2012) 49-59. doi:10.1016/j.memsci.2012.01.025.

[8] B. Zhang, S. Gu, J. Wang, Y. Liu, A.M. Herring, Y. Yan, Tertiary sulfonium as a cationic functional group for hydroxide exchange membranes, RSC Advances. 2 (2012) 12683-12685. doi:10.1039/c2ra21402d.

[9] Y. Zha, M.L. Disabb-Miller, Z.D. Johnson, M.A. Hickner, G.N. Tew, Metal-CationBased Anion Exchange Membranes, J. Am. Chem. Soc. 134 (2012) 4493-4496. doi:10.1021/ja211365r. 
[10] Y. Liu, J. Wang, Y. Yang, T.M. Brenner, S. Seifert, Y. Yan, et al., Anion Transport in a Chemically Stable, Sterically Bulky $\alpha-C$ Modified Imidazolium Functionalized Anion Exchange Membrane, J. Phys. Chem. C. 118 (2014) 15136-15145. doi:10.1021/jp5027674.

[11] R. Borup, J. Meyers, B. Pivovar, Y.S. Kim, R. Mukundan, N. Garland, et al., Scientific Aspects of Polymer Electrolyte Fuel Cell Durability and Degradation, Chem. Rev. 107 (2007) 3904-3951. doi:10.1021/cr0501821.

[12] T.-H. Tsai, A.M. Maes, M.A. Vandiver, C. Versek, S. Seifert, M. Tuominen, et al., Synthesis and structure-conductivity relationship of polystyrene- block-poly(vinyl benzyl trimethylammonium) for alkaline anion exchange membrane fuel cells, J Polym Sci Pol Phys. 51 (2012) 1751-1760. doi:10.1002/polb.23170.

[13] M.A. Vandiver, B.R. Caire, Z. Poskin, Y. Li, Durability and performance of polystyrene- b- poly (vinylbenzyl trimethylammonium) diblock copolymer and equivalent blend anion exchange membranes, Journal of Applied ... 132 (2015) 41596. doi:10.1002/app.41596.

[14] T.-H. Tsai, Ionic Copolymers for Alkaline Anion Exchange Membrane Fuel Cells, University of Massachusetts Amherst, 2014.

[15] T.J. Clark, N.J. Robertson, H.A. Kostalik IV, E.B. Lobkovsky, P.F. Mutolo, H.D. Abruña, et al., A Ring-Opening Metathesis Polymerization Route to Alkaline Anion Exchange Membranes: Development of Hydroxide-Conducting Thin Films from an Ammonium-Functionalized Monomer, J. Am. Chem. Soc. 131 (2009) 12888-12889. doi:10.1021/ja905242r.

[16] H.A. Kostalik IV, T.J. Clark, N.J. Robertson, P.F. Mutolo, J.M. Longo, H.D. Abruña, et al., Solvent Processable Tetraalkylammonium-Functionalized Polyethylene for Use as an Alkaline Anion Exchange Membrane, Macromolecules. 43 (2010) 7147-7150. doi:10.1021/ma101172a.

[17] M. Zhang, H.K. Kim, E. Chalkova, F. Mark, S.N. Lvov, T.C.M. Chung, New Polyethylene Based Anion Exchange Membranes (PE-AEMs) with High Ionic Conductivity, Macromolecules. 44 (2011) 5937-5946. doi:10.1021/ma200836d.

[18] M. Faraj, M. Boccia, H. Miller, F. Martini, S. Borsacchi, M. Geppi, et al., New LDPE based anion-exchange membranes for alkaline solid polymeric electrolyte water electrolysis, International Journal of Hydrogen Energy. 37 (2012) 14992-15002. doi:10.1016/j.ijhydene.2012.08.012.

[19] T.A. Sherazi, J.Y. Sohn, Y.M. Lee, M.D. Guiver, Polyethylene-based radiation grafted anion-exchange membranes for alkaline fuel cells, J Membrane Sci. 441 (2013) 148-157. doi:10.1016/j.memsci.2013.03.053.

[20] M.P. Rodgers, L.J. Bonville, H.R. Kunz, D.K. Slattery, J.M. Fenton, Fuel Cell Perfluorinated Sulfonic Acid Membrane Degradation Correlating Accelerated Stress Testing and Lifetime, Chem. Rev. 112 (2012) 6075-6103. doi:10.1021/cr200424d.

[21] T.T. Aindow, J. O'Neill, Use of mechanical tests to predict durability of polymer fuel cell membranes under humidity cycling, Journal of Power Sources. 196 (2011) 38513854. doi:10.1016/j.jpowsour.2010.12.031.

[22] H. Tang, S. Peikang, S.P. Jiang, F. Wang, M. Pan, A degradation study of Nafion proton exchange membrane of PEM fuel cells, Journal of Power Sources. 170 (2007) 85-92. doi:10.1016/j.jpowsour.2007.03.061.

[23] M. Pestrak, Y. Li, S.W. Case, D.A. Dillard, M.W. Ellis, Y.-H. Lai, et al., The effect of 
mechanical fatigue on the lifetimes of membrane electrode assemblies, J. Fuel Cell Sci. Technol. 7 (2010) 041009. doi:10.1115/1.4000629.

[24] Y.P. Patil, W.L. Jarrett, K.A. Mauritz, Deterioration of mechanical properties: a cause for fuel cell membrane failure, J Membrane Sci. 356 (2010) 7-13. doi:10.1016/j.memsci.2010.02.060.

[25] M.A. Vandiver, B.R. Caire, J.R. Carver, K. Waldrop, M.R. Hibbs, J.R. Varcoe, et al., Mechanical Characterization of Anion Exchange Membranes by Extensional Rheology under Controlled Hydration, J. Electrochem. Soc. 161 (2014) H677-H683. doi:10.1149/2.0971410jes.

[26] Y. Li, Block Copolymer for Alkaline Fuel Cell Membrane Materials, Colorado School of Mines, 2014.

[27] T.P. Pandey, A.M. Maes, H.N. Sarode, B.D. Peters, S. Lavina, K. Vezzu, et al., Interplay between water uptake, ion interactions, and conductivity in an e-beam grafted poly(ethylene-co-tetrafluoroethylene) anion exchange membrane, Phys. Chem. Chem. Phys. 17 (2015) 4367-4378. doi:10.1039/C4CP05755D.

[28] M. Sentmanat, S.G. Hatzikiriakos, Mechanism of gross melt fracture elimination in the extrusion of polyethylenes in the presence of boron nitride, Rheol Acta. 43 (2004) 624633. doi:10.1007/s00397-004-0359-6.

[29] B.R. Caire, M.A. Vandiver, M.W. Liberatore, Mechanical testing of small, thin samples in a humidity-controlled oven, Rheol Acta. (2015). doi:10.1007/s00397-014-0834-7.

[30] J. Yan, M.A. Hickner, Anion Exchange Membranes by Bromination of BenzylmethylContaining Poly(sulfone)s, Macromolecules. 43 (2010) 2349-2356. doi:10.1021/ma902430y.

[31] Y. Li, A.C. Jackson, F.L. Beyer, D.M. Knauss, Poly(2,6-dimethyl-1,4-phenylene oxide) Blended with Poly(vinylbenzyl chloride)- b-polystyrene for the Formation of Anion Exchange Membranes, Macromolecules. (2014) 140923073242003. doi:10.1021/ma500993s.

[32] R. Halseid, P.J.S. Vie, R. Tunold, Influence of ammonium on conductivity and water content of Nafion 117 membranes, J. Electrochem. Soc. 151 (2004) A381. doi:10.1149/1.1641035.

[33] M.A. Vandiver, J.L. Horan, Y. Yang, E.T. Tansey, S. Seifert, M.W. Liberatore, et al., Synthesis and characterization of perfluoro quaternary ammonium anion exchange membranes, J Polym Sci Pol Phys. 51 (2013) 1761-1769. doi:10.1002/polb.23171.

[34] R.C.T. Slade, J.R. Varcoe, Investigations of conductivity in FEP-based radiation-grafted alkaline anion-exchange membranes, Solid State Ionics. 176 (2005) 585-597. doi:10.1016/j.ssi.2004.09.044.

[35] C. Fujimoto, D.-S. Kim, M. Hibbs, D. Wrobleski, Y.S. Kim, Backbone stability of quaternized polyaromatics for alkaline membrane fuel cells, J Membrane Sci. 423-424 (2012) 438-449. doi:10.1016/j.memsci.2012.08.045.

[36] A.M. Park, P.N. Pintauro, Alkaline Fuel Cell Membranes from Electrospun Fiber Mats, Electrochem Solid St. 15 (2012) B27. doi:10.1149/2.010203esl.

[37] N.J. Robertson, H.A. Kostalik IV, T.J. Clark, P.F. Mutolo, H.D. Abruña, G.W. Coates, Tunable high performance cross-linked alkaline anion exchange membranes for fuel cell applications, J. Am. Chem. Soc. 132 (2010) 3400-3404. doi:10.1021/ja908638d.

[38] K.P. Menard, Dynamic Mechanical Analysis, A Practical Introduction, 2nd ed., CRC Press, Inc, Boca Raton, 2008. 
[39] M.-C. Ferrari, J. Catalano, M. Giacinti Baschetti, M.G. De Angelis, G.C. Sarti, FTIRATR Study of Water Distribution in a Short-Side-Chain PFSI Membrane, Macromolecules. 45 (2012) 1901-1912. doi:10.1021/ma202099p.

[40] Z.H. Ping, Q.T. Nguyen, S.M. Chen, J.Q. Zhou, Y.D. Ding, States of water in different hydrophilic polymers_-DSC and FTIR studies, Polymer. 42 (2001) 8461-8467.

[41] K. Kunimatsu, B. Bae, K. Miyatake, H. Uchida, M. Watanabe, ATR-FTIR Study of Water in Nafion Membrane Combined with Proton Conductivity Measurements during Hydration/Dehydration Cycle, J. Phys. Chem. B. 115 (2011) 4315-4321. doi:10.1021/jp112300c.

[42] J. Benziger, A. Bocarsly, M.J. Cheah, P. Majsztrik, B. Satterfield, Q. Zhao, Mechanical and Tranport Properties of Nafion: Effects of Temperature and Water Activity, in: A. Bocarsly, D.M.P. Mingos (Eds.), Fuel Cells and Hydrogen Storage, Springer Berlin Heidelberg, 2011: pp. 85-113. doi:10.1007/430_2011_41.

[43] Q. Duan, S. Ge, C.-Y. Wang, Water uptake, ionic conductivity and swelling properties of anion-exchange membrane, Journal of Power Sources. 243 (2013) 773-778. doi:10.1016/j.jpowsour.2013.06.095. 
Effect of hydration on the mechanical properties and ion conduction in a polyethylene-bpoly(vinylbenzyl trimethylammonium) anion exchange membrane

Melissa A. Vandiver ${ }^{1}$, Benjamin R. Caire ${ }^{1}$, Tara P. Pandey ${ }^{1}$, Yifan Li ${ }^{2}$, Sönke Seifert ${ }^{3}$, Ahmet Kusoglu ${ }^{4}$, Daniel M. Knauss ${ }^{2}$, Andrew M. Herring ${ }^{1}$, Matthew W. Liberatore ${ }^{1 *}$

${ }^{1}$ Department of Chemical and Biological Engineering and ${ }^{2}$ Department of Chemistry and Geochemistry, Colorado School of Mines, Golden, CO 80401

${ }^{3}$ X-Ray Science Division, Argonne National Laboratory, Argonne, Illinois 60439

${ }^{4}$ Electrochemical Technologies Group, Lawrence Berkeley National Laboratory, Berkeley, CA 94720

*Corresponding author: mliberat @ mines.edu

Graphical abstract

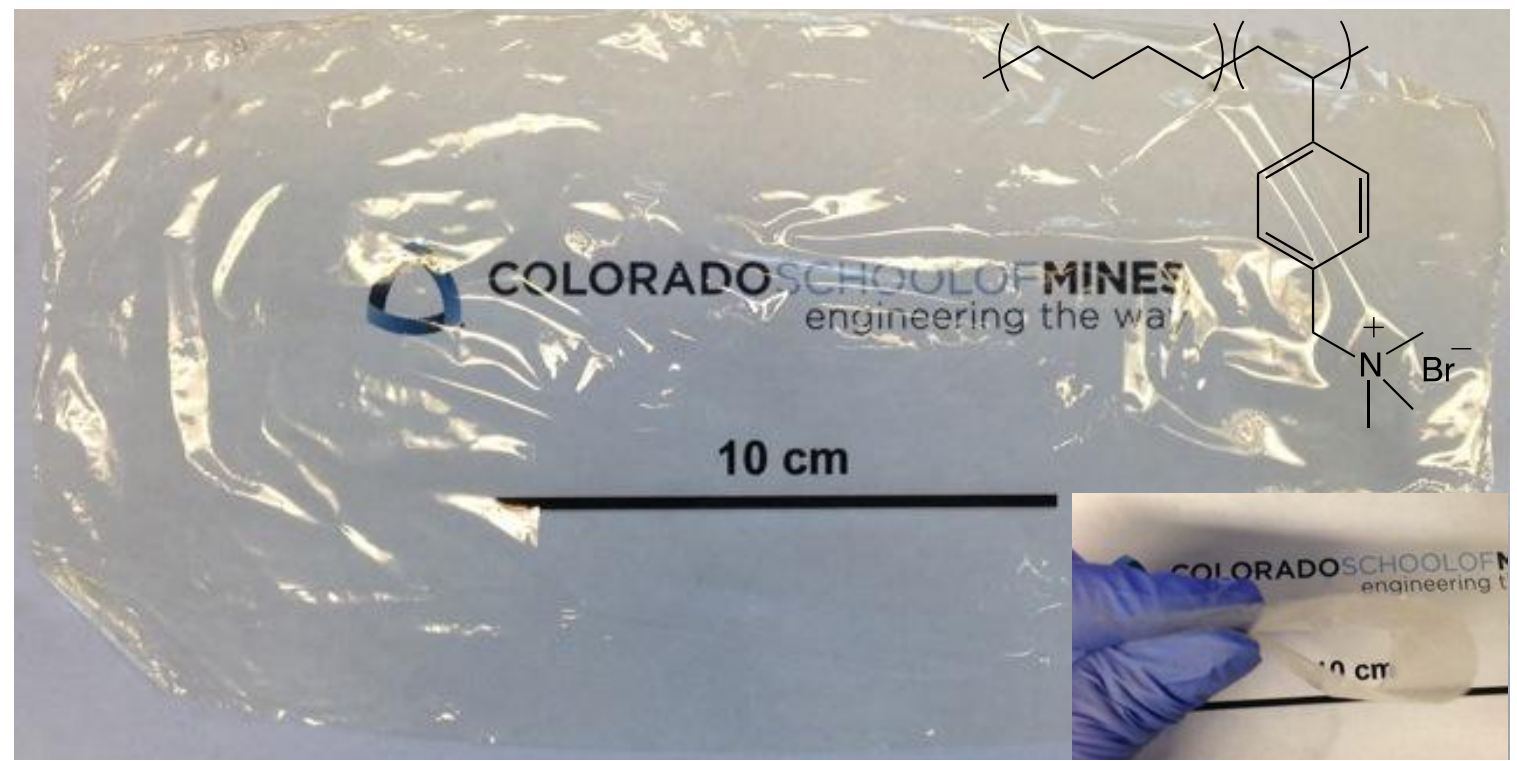

